\title{
Penyuluhan Ibu Hamil dengan Tablet Fe, Nutrisi Ibu Hamil dan Tanda Bahaya Ibu di Wilayah Kelurahan Jenggot Kota Pekalongan
}

\author{
Mitachul Jannah ${ }^{1}$, Swasti Artanti ${ }^{2}$ \\ email : miftachuljannsh88@gmail.com \\ Akademi Kebidanan Harapan Ibu Pekalongan \\ Jl. Sriwijaya No 7 Pekalongan \\ Telp/Fax (0285) 4416108
}

\begin{abstract}
Abstrak
Program pengabdian kepada masyarakat dengan topik "Penyuluhan Ibu Hamil dengan Tablet Fe, Nutrisi Ibu Hamil dan Tanda Bahaya Ibu Hamil di Wilayah Kelurahan Jenggot Kota Pekalongan" ditujukan kepada ibu - ibu hamil Trimester II dan III untuk memberikan pengetahuan mengenai pengetahuan ibu hamil tentang manfaatnya tablet Fe, kebutuhan nutrisi selama kehamilan dan tanda bahaya kehamilan diwilayah kelurahan jenggot kota pekalongan. Pentingnya memberikan edukasi tentang sosialisasi pada ibu hamil seputar manfaat tablet fe selama kehamilan karena bagi tubuh ibu hamil diperlukan hemoglobin. Selama kehamilan ibu hamil perlu memerlukan makanan yang bernutrisi tinggi dan cukup bagi dirinya maupun janinnya. Jika ibu hamil kekurangan nutrisi dan zat besi selama kehamilan akan menimbulkan masalah, baik pada ibu maupun janin yang dkandungnya. Faktor keluarga dan lingkungan akan sangat berpengaruh pada ibu hamil. Harapannya, ibu hamil tidak ada pantang makan. Kegiatan ini bisa berkesinambungan dan mendorong ibu hamil untuk peduli selama kehamilan baik minum tablet fe, makan-makan yang bergizi dan mengerti tanda bahaya selama kehamilan. Selain itu, dilakukan Pre Test dan Post Test untuk mengetahui tingkat pengetahuan sebelum dan sesudah penyuluhan. Hasil yang diperoleh yaitu terdapat peningkatan yang signifikan pada ibu-ibu hamil di wilayah kelurahan jenggot kota pekalongan setelah dilakukan penyuluhan mengenai tablet fe, nutrisi ibu hamil dan tanda bahaya kehamilan.
\end{abstract}

Kata kunci : Tablet Fe, Nutrisi Ibu Hamil, Tanda Bahaya Kehamilan, Ibu Hamil.

\begin{abstract}
Community service program with the topic "Counseling Pregnant Women with Fe Tablets, Nutrition for Pregnant Women and Dangerous Signs of Pregnant Women in Jenggot, Pekalongan City" is aimed at Trimester II and III pregnant women to provide about pregnant women's knowledge about the benefits of Fe tablets, nutritional needs during pregnancy and pregnancy danger signs in the area of Jenggot, Pekalongan city. It is important to educate pregnant women about the benefits of Fe tablets during pregnancy because hemoglobin is needed for the body of pregnant women. During pregnancy, a pregnant woman needs to have high nutritious food and is sufficient for herself and her fetus. If a pregnant woman lacks nutrition and iron during pregnancy, it will cause problems, both for the mother and the fetus. Family and environmental factors will greatly affect pregnant women. Hopefully, pregnant women will have no abstinence to eat. This activity can be sustainable and encourage pregnant women to care during pregnancy whether to take $\mathrm{Fe}$ tablets, eat nutritious foods and understand the danger signs during pregnancy. In addition, a Pre Test and Post Test were conducted to determine the level of knowledge before and after counseling. The results obtained are that there is a significant increase in pregnant women in Jenggot, Pekalongan after counseling about Fe tablets, nutrition of pregnant women and pregnancy danger signs.
\end{abstract}

Keywords: Fe tablets, nutrition of pregnant women, danger signs of pregnancy, pregnant women. 


\section{Pendahuluan}

Angka Kematian Ibu merupakan salah satu indikator derajat kesejahteraan suatu negara. Oleh karena itu, berbagai program terus diupayakan untuk menurunkan angka tersebut. AKI mengacu pada jumlah kematian ibu yang terkait dengan masa kehamilan, persalinan dan nifas. ${ }^{(1)}$

Indonesia sebagai salah satu negara berkembang menempati urutan AKI tertinggi se-Asia Tenggara pada tahun 2014 yaitu 214 per $100.000 \mathrm{KH}$, diikuti dengan Fhilipina 170, Vietnam 160, Thailand 44, Brunei 60, dan Malaysia 39 per $100.000 \mathrm{KH}$. Tingginya angka kematian ini menggambarkan masih rendahnya derajat kesehatan masyarakat dan berpotensi menyebabkan kemunduran ekonomi dan sosial level rumah tangga, komunitas, dan nasional.

Berbagai upaya dilakukan oleh Pemerintah untuk menurunkan AKI. Upaya tersebut antara lain adalah penempatan bidan desa, Buku Kesehatan Ibu dan Anak (Buku KIA), Program Perencanaan Persalinan dan Pencegahan Komplikasi (P4K), penyediaan fasilitas kesehatan Pelayanan Obstetri Neonatal Emergensi Dasar (PONED) di Puskesmas perawatan, Pelayanan Obstetri Neonatal Emergensi Komprehensif (PONEK) di rumah sakit. Selain itu, juga dilakukan layanan konsultasi saat pemeriksaan rutin kandungan maupun kunjungan Posyandu. Namun, konsultasi tersebut hanya mencakup layanan penyuluhan untuk kasus per kasus, hanya dilakukan saat ibu datang untuk konsultasi, pengetahuan yang diperoleh terbatas pada masalah yang dihadapi saat konsultasi, materi penyuluhannya tidak terkoordinir dan tidak dilaksanakan dengan terjadwal dan berkesinambungan. ${ }^{(2)}$

Kekurangan-kekurangan

tersebut perlu diatasi, maka dibutuhkan upaya peningkatan pengetahuan dan perubahan perilaku ibu serta keluarga agar lebih menyadari pentingnya kesehatan khususnya pada masa kehamilan. Program Kementerian Kesehatan untuk mendukung langkah tersebut adalah Kelas Ibu Hamil.

Kebutuhan nutrisi setiap ibu hamil berbeda beda hal ini dikarenakan karena adanya janin yang tumbuh dirahimnya. Kebutuhan nutrisi dilihat bukan hanya dalam porsi tetapi harus ditentukan pada mutu zat-zat nutrisi yang terkandung dalam makanan yang dikonsumsi. ${ }^{(4)}$ Selain nutrisi kebutuhan penting lainya yang harus dipenuhi selama kehamilan yaitu zat besi, dikarenakan pada periode kehamilan TM I dan TM III ibu hamil mengalami hemodilusi atau pengenceran darah sehingga pada trimester tersebut kebutuhan zat besi pada ibu hamil meningkat. Zat besi adalah salah satu mineral yang berperan penting untuk membentuk hemoglobin di dalam sel darah merah. Hemoglobin bertugas mengikat dan mengirimkan oksigen ke seluruh tubuh. Tablet tabah darah atau tablet besi adalah suplemen yang mengandung zat besi.Zat besi adalah mineral yang dibutuhkan untuk membentuk sel darah merah (Hemoglobin). ${ }^{(3)}$

Bila ibu hamil mengalami kekurangan nutrisi dan zat besi selama hamil akan menimbulkan masalah, baik pada ibu maupun janin yang dikandungnya yaitu anemia, perdarahan, berat badan ibu tidak bertambah secara normal. kurang nutrisi juga dapat mempengaruhi proses persalinan dimana dapat mengakibatkan 
persalinan sulit dan lama, prematur, perdarahan setelah persalinan, kurang nutrisi juga dapat mempengaruhi pertumbuhan janin dandapat menimbulkan keguguran, abortus, cacat bawaan dan berat janin bayi lahir rendah. ${ }^{(4)}$

Kehamilan dan melahirkan menimbulkan resiko kesehatan yang besar,termasuk bagi perempuan yang tidak mempunyai masalah kesehatan sebelumnya. Kira-kira $\quad 40 \quad \%$ ibu hamil mengalami masalah kesehatan berkaitandengan kehamilan dan 15 $\%$ dari semua ibu hamil menderita komplikasi jangka panjang yang mengancam jiwa bahkan sampai menimbulkan kematian. Pengawasan sebelum lahir (antenatal) terbukti mempunyai kedudukan yang sangat penting dalam upaya meningkatkan kesehatan mental dan fisik, untuk menghadapi persalinan. Dengan pengawasan hamil dapat diketahui berbagai komplikasi ibu yang dapat mempengaruhi kehamilan atau komplikasi hamil sehingga dapat segera diatasi. Yang tidak mungkin dapat diatasi segeradirujuk ke tempat yang lebih lengkap peralatannya sehingga mendapat perawatan yang optimal.

Berdasarkan paparan di atas tentang pentingnya kelas ibu hamil, maka penulis tertarik untuk melasanakan pengabdian kepada masyarakat yang berjudul "Penyuluhan Ibu Hamil dengan Tablet Fe, Nutrisi Ibu Hamil dan Tanda Bahaya Ibu Hamil di Wilayah Kelurahan Jenggot Kota Pekalongan".

\section{Metode}

Pelaksanaan kegiatan pengabdian masyarakat ini, sesuai dengan tahapan sebagai berikut:

A. Metode Pendekatan.

1) Melakukan pendekatan dengan pihak kelurahan, seperti kepala kelurahan, kader dan bidan desa

2) Melakukan diskusi, penugasan, dan strategi dengan tim

3) Membangun Komitmen Bersama yang dituangkan dalam bentuk kegiatan pada tahun 2019.

B. Tahap Persiapan

Metode yang dilakukan sebelum kegiatan adalah:

1) Melakukan studi pendahuluan situasi

2) Melakukan koordinasi dengan Tim Dosen Pengabmas dan Mahasiswa.

3) Melakukan advokasi dan koordinasi tentang peran serta dan tugas mitra.

4) Menyiapkan tempat dan peralatan.

C. Rencana kegiatan

1) Melakukan Pretest

2) Menyampaikan materi Tablet Fe, Nutrisi Ibu Hamil dan Tanda Bahaya

Kehamilan

3) Melakukan Pos-test

4) Menilai hasil pre test postest.

D. Partisipasi Mitra

1) Mengumpulkan seluruh ibu hamil yang ada diwilayah keluarahan jenggot untuk mengikuti pre-test.

2) Mempersiapkan tempat, dan waktu untuk kegiatan pretest

3) Mempersiapkan pelaksanaan penyampaian materi Tablet $\mathrm{Fe}$, Nutrisi Ibu Hamil dan Tanda Bahaya Kehamilan

4) Mempersiapkan evaluasi secara bersama.

\section{Hasil dan Pembahasan}

Kelurahan Jenggot Kota Pekalongan adalah mitra dari kegiatan pengabdian kepada 
masyarakat serta belum terpapar dengan penyuluhan seputar kesehatan ibu hamil. Kegiatan pegabdian kepada masyarakat tersebut berupa penyuluhan dengan memberikan informasi serta memaparkan konsep mengenai peningkatan pengetahuan ibu hamil selama kehamilan 9 bulan kemudian meminta bantuan kepada pihak kelurahan Jenggot untuk bersamasama mempersiapkan acara kegiatan pengabdian kepada masyarakat dengan hasil :

Diagram 1 Hasil pengukuran pengetahuan ibu hamil tentang tablet tambah darah.

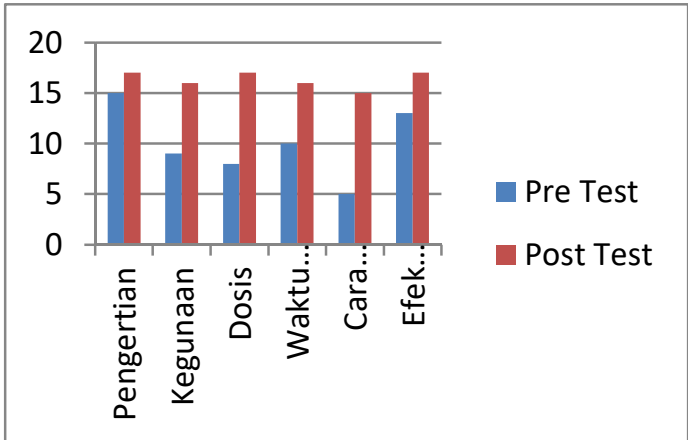

Berdasarkan diagram diatas dapat dilihat bahwa pengetahuan ibu hamil tentang tablet tambah darah sebelum diberikan penyuluhan dengan setelah diberikan penyuluhan mengalami peningkatan sebesar $95 \%$.

Diagram 2 Hasil pengukuran pengetahuan ibu hamil tentang nutrisi ibu hamil.

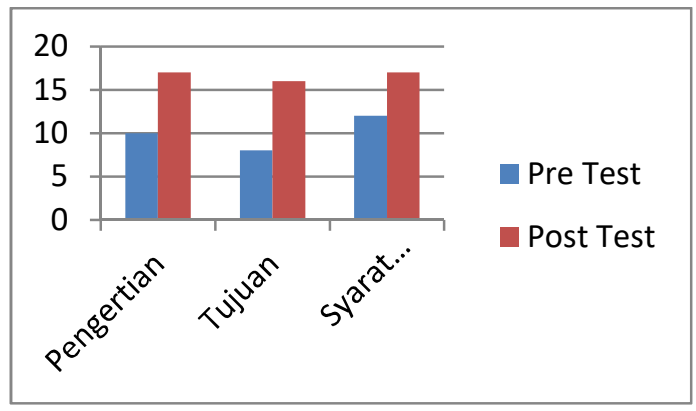

Berdasarkan diagram diatas dapat dilihat bahwa pengetahuan ibu hamil tentang nutrisi pada ibu hamil sebelum diberikan penyuluhan dengan setelah diberikan penyuluhan mengalami peningkatan sebesar $87 \%$.

Diagram 3 Hasil pengukuran pengetahuan ibu hamil tentang tanda bahaya kehamilan.

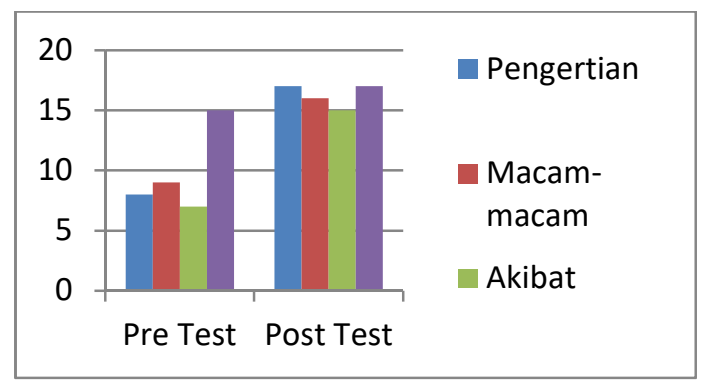

Berdasarkan diagram diatas dapat dilihat bahwa pengetahuan ibu hamil tentang tanda bahaya kehamilan sebelum diberikan penyuluhan dengan setelah diberikan penyuluhan mengalami peningkatan sebesar $90 \%$.

Dari hasil evaluasi Pre test dan Postest ada perbedaan peningkatan pengetahuan sebelum dan sesudah pemberian materi tersebut, yang semula hanya 45 - 55\% tahu setelah dilakukannya sosialisasi dan penyampaian materi. meningkat menjadi 80 - 95\%. Hasil dari kegiatan ini dapat berjalan dan dapat di terima dengan baik,dengan ditandai, tingkat ketertarikan dan antusias ibu hamil dalam kegiatan ini dan dari Evaluasi Pre test dan Postest ada perbedaan peningkatan pengetahuan sebelum dan sesudah pemberian materi tersebut.

\section{Kesimpulan}

Pelaksanaan kegiatan pengabdian masyarakat "Penyuluhan Ibu Hamil dengan Tablet Fe, Nutrisi Ibu Hamil dan Tanda Bahaya Ibu Hamil di Wilayah Kelurahan Jenggot Kota Pekalongan" dapat diterima oleh 
mitra dan terkoordinasi dengan baik. Bertambahnya pengetahuan dari ibu hamil setelah dilakukan pre test kemudian dan post test, yang semula hanya $45-55 \%$ tahu setelah dilakukannya sosialisasi dan penyampaian materi meningkat menjadi 87 - $95 \%$. Pihak Kelurahan agar lebih aktif mensosialisasikan tentang apa saja yang penting buat ibu hamil kepada ibu hamil baik dengan pihak Fasilitas Pelayanan Kesehatan, Tenaga Kesehatan, Akademisi atau instasi-instasi lain yang bersangkutan, untuk selalu memberikan penyuluhanpenyululuhan bagi ibu hamil.

\section{Daftar Pustaka}

[1] Depkes RI. 2010. Riset Kesehatan Dasar Tahun 2010. Jakarta: Badan Penelitian dan Pengembangan Kesehatan Depkes RI.
[2] Heri D.J. Maulana. 2009. Promosi Kesehatan. Jakarta : EGC.

[3] R. Angrainy, "Hubungan Pengetahuan dengan Sikap Ibu Hamil dalam Pencegahan Anemia Pada Kehamilan Di Puskesmas Rumbai Bukit Tahun 2016,"J. Endur., 2017.

[4] F. Rizki, D. Atmono, A. Widodo, and P. Wulandari, "Faktor Risiko Penyakit Anemia Gizi Besi pada Ibu Hamil di Jawa Timur Menggunakan Analisis Regresi Logistik," J. Sains dan Seni ITS, 2015. 